\title{
Grafting of amino groups onto carbon fibers by bromination followed by
}

\section{ammonolysis}

\author{
Liudmyla M. Grishchenko ${ }^{a^{*}}$, Tetiana M. Bezugla ${ }^{a}$, Anna V. Vakaliuk ${ }^{\mathrm{a}}$, \\ Galyna G. Tsapyuk ${ }^{\mathrm{a}}$, Oleksandr V. Mischanchuk ${ }^{\mathrm{b}}$, \\ Olga Yu. Boldyrieva ${ }^{a}$, Vitaliy E. Diyuk ${ }^{\mathrm{a}}$ \\ ${ }^{a}$ Department of Chemistry, Taras Shevchenko National University of Kyiv, Volodymyrska Street, \\ 64/13, Kyiv 01601, Ukraine \\ ${ }^{b}$ Chuiko Institute of Surface Chemistry of National Academy of Sciences of Ukraine \\ General Naumov Street 17, Kyiv 03164, Ukraine \\ liudmyla.grishchenko@gmail.com
}

Keywords: Carbon fibers (CFs), surface amino groups, bromination followed by ammonolysis Because of the low content of chelating groups onto carbon fibers (CFs), their adsorptive parameters are poor, and this has negative effects on their applications as lightweight sorbents. In this work, we established a modification method to incorporate amine groups into carbon fiber surfaces by bromination followed by ammonolysis to create an interfacial layer which can adsorb heavy metal ions from solutions. The changed chemical composition, surface morphology, and thermal stability were investigated. Thermoprogrammed desorption mass-spectrometry and thermal analysis showed thermal transformation and interplay between forms of the grafted bromine groups of $0.5 \mathrm{mmol} / \mathrm{g}$ and the resulting amino groups of $0.44-0.56 \mathrm{mmol} / \mathrm{g}$. After grafting, the surface chemistry parameters were improved due to the covalent bonding and grafting of the amine groups as interface modifier. Scanning electron microscopy observation also confirmed that the surface morphology maintains the same, without impairment of fiber properties. This work is therefore a beneficial approach towards enhancing the adsorption parameters by controlling the interface layer of CFs.

\section{Introduction}

Among industrial by-products, polyacrylonitrile (PAN) with abundant nitrile groups is of special interest for preparing advanced sorbents. However, it has almost no binding ability toward metal ions. For example, grafting branched polyethyleneimine onto PAN fibers is necessary for the efficient removal of $\mathrm{Cu}^{2+}$ from industrial wastewater [1]. In the presentday, PAN is known primary source material for preparing carbon fibers (CFs), rayon CFs, or pitch precursor CFs. Lightweight CFs have been used in chemical engineering, aerospace and military defense, and biomedicine because of their low density, high specific 
strength, and high thermal stability [2,3]. As promising sorbents, nanofibers with a high specific surface area and high adsorption site loading will show excellent adsorption capacity $[4,5]$. For these reasons, varieties of methods regarding surface modifications of CFs were established to improve the adsorptive capacity, such as oxidation treatment, plasma, and ammonia treatment $[6$, 7, 8]. Previous studies have proved that the effective adsorptive properties of the CFs depend on the fiber interface quality. Changing the distribution of the electron densities on the graphite carbon surface, the introduced nitrogen-containing functional groups may generate the various electrocatalytic and catalytic activities $[9,10]$. By the glassy carbon electrode oxidation in an ammonium carbamate solution, one can introduce some kinds of amine groups to the glassy carbon surface. The resulting electrode modified by amine groups can be used for the electrocatalytic redox reactions of inorganic and organic compounds. Cyclic voltammograms of metal ions and metal chelate compounds can be registered by using the aminated glassy carbon electrode $[9,11]$. However, this method has low selectivity with respect to grafted amino groups. A mix of primary, secondary, and tertiary amines was found from the fitting of $\mathrm{N}$ core level $\mathrm{X}$ ray photoelectron spectra. The same is true for the treatment by an ammoniac medium of supercritical water, ethanol, and triethylenetetramine [12]. According to X-ray photoelectron spectroscopy studies, the resulting CFs demonstrated the increased $\mathrm{N}$ content sourced from the amino and imino groups. Microporous nitrogen enriched $\mathrm{CFs}$ can be produced by pyrolysis/activation of fiber from anthracene oil-based pitch in ammonia atmosphere [11]. Thus, the intensive reaction of pitches with ammonia is a high-temperature process taking place at 750-800 ${ }^{\circ} \mathrm{C}$. Zabihi et al. [15] demonstrated an efficient method for covalent functionalization of PAN-based carbon fibers by in situ produced radicals taking place under mild reaction condition. In such azo radical addition, isobutyronitrile radicals that are the products of thermal decomposition of $2,2^{\prime}$-azobisisobutyronitrile can be covalently grafted on the carbon fiber surface. Exposure to plasma in the presence of ammonia is a promising route to aminate the surface of Aramid fibers [2]. The exposed fibers show no decrease in the tensile strength decrease and no increase in surface area. The surface amine concentration rapidly grows with plasma exposure, reaching a steady state in up to $1 \mathrm{~min}$. $\mathrm{Wu}$ and Tesoro [16] investigated organic reactions of model aromatic diamides to select reagents and conditions suitable for controlled heterogeneous surface reactions on Kevlar filaments and fabrics. Amine functional groups have been incorporated into 
fiber surfaces by bromination followed by ammonolysis and by nitration followed by reduction [7, 16]. We suggested that bromination followed by ammonolysis may be suitable reaction sequence for functionalization of CFs prepared from PAN fabric. We encourage from the fact that in modern studies, insufficient attention is paid to the chemical modification of the surface of CFs and to the thermal studies of the materials obtained, and therefore to the bromination techniques giving significant concentrations of covalently bonded bromine capable substituting for other functional groups. Based on the discussions above, it can be maintained that grafting amino groups on the CF surface may produce a synergistic effect on improving the adsorptive properties. In this study, we choose amine groups as the modifiers and grafted them onto CFs by covalent linkage. We expected that the grafted amino groups are beneficial to the improvement of specific capacity towards heavy metal cations. Here, we focused on the synthetic issue and reported the results of thermal analysis of the aminated surface layer of CFs functionalized by bromination followed by ammonolysis.

\section{Experimental part}

\subsection{Materials}

Commercial CFs were provided by Sokhim Co, (Svetlogorsk, Belarus). Chemicals, including bromine and amines, were supplied by Aldrich Co, Ukrreakhim, and UkrOrgSyntez Ltd.

\subsection{Bromination followed by ammonolysis}

A sample of $5 \mathrm{~g}$ weight $\mathrm{CF}$ was treated with $10 \mathrm{ml}$ of liquid bromine at $20{ }^{\circ} \mathrm{C}$ for $1 \mathrm{~h}$. For comparison reasons, we also treated CFs by $50 \mathrm{ml}$ of an aqueous solution containing $10 \%(\mathrm{v} / \mathrm{v}) \mathrm{Br}_{2}$ and $15 \%(\mathrm{w} / \mathrm{v}) \mathrm{KBr}$. The brominated CFs were treated with $200 \mathrm{ml}$ of a $10 \%(\mathrm{w} / \mathrm{v})$ solution of potassium oxalate to fix physisorbed and intercalated dibromine. When $\mathrm{CO}_{2}$ gassing ceased, the brominated CFs were filtered and washed with water until no bromide ions were registered in the washing waters. The resulting samples were dried in air at $120{ }^{\circ} \mathrm{C}$ and labeled as $\mathrm{CF} / \mathrm{Br}_{2}$ and $\mathrm{CF} / \mathrm{KBr}_{3}$. Ethylenediamine (En), sulfonanylethylenediamine (SuEn), diethylamine $\left(\mathrm{Et}_{2} \mathrm{~N}\right)$, monoethanolamine (MEA), and piperazine (Py) were chosen for grafting of amino groups, which designations were showed as in the resulting CFs names, e.g. $\mathrm{CF} / \mathrm{Br}_{2} / \mathrm{Et}_{2} \mathrm{~N}$. These amines were purified by steam distillation. In ammonolysis, $1 \mathrm{~g}$ $\mathrm{CF} / \mathrm{Br}_{2}$ and an excess of $20 \%$ amine alcohol solution were reacted in an autoclave at 110 $120{ }^{\circ} \mathrm{C}$ for $15 \mathrm{~h}$. After ammonolytic treatment, the resulting CFs were washed with distilled water and hydrochloric acid to remove the physisorbed amine, and then with distilled water again to neutralize acid residues, and dried in air at $120^{\circ} \mathrm{C}$. 


\subsection{Characterization}

The total bromine in the samples was determined by the Volgard method, using pretreatment reported in [17]. Thermodesorption studies were performed using thermoprogrammed desorption mass spectrometry (TPD MS) and thermogravimetry (TGA) methods. Thermal analysis was carried out in the temperature range of $30-800{ }^{\circ} \mathrm{C}$ at a heating rate of 10 ${ }^{\circ} \mathrm{C} / \mathrm{min}$. TPD MS were registered on a mass spectrometer MX 7304 A. Thermogravimetric studies in dynamic argon atmosphere were done as reported elsewhere in [18]. The total number of acid sites was determined by the titrimetric method [19]. The TGA method was used to estimate the concentration of grafted amines. From thermogravimetry (TG) and derivative thermogravimetry (DTG) data were used to find the total weight loss $(\Delta m)$, desorption peak temperature of $\mathrm{HBr}\left(T_{i}\right.$, where $i=1$ and 2) and amines ( $\left.T_{\max }\right)$, temperature ranges of bromine and amino groups decomposition ( $\Delta t_{b}$ and $\Delta t_{a}$ ), and the weight loss for selected temperature range $(\Delta m / \Delta t)$.

\section{Results and discussion}

Figure 1 shows CF having the value of the specific Brunauer-Emmett-Teller surface $S_{\mathrm{BET}}=950 \mathrm{~m}^{2} / \mathrm{g}$ and the total sorption pore volume $\left(V_{\mathrm{S}}\right)$ of $0.19 \mathrm{~cm}^{3} / \mathrm{g}$ that was determined by water physisorption.

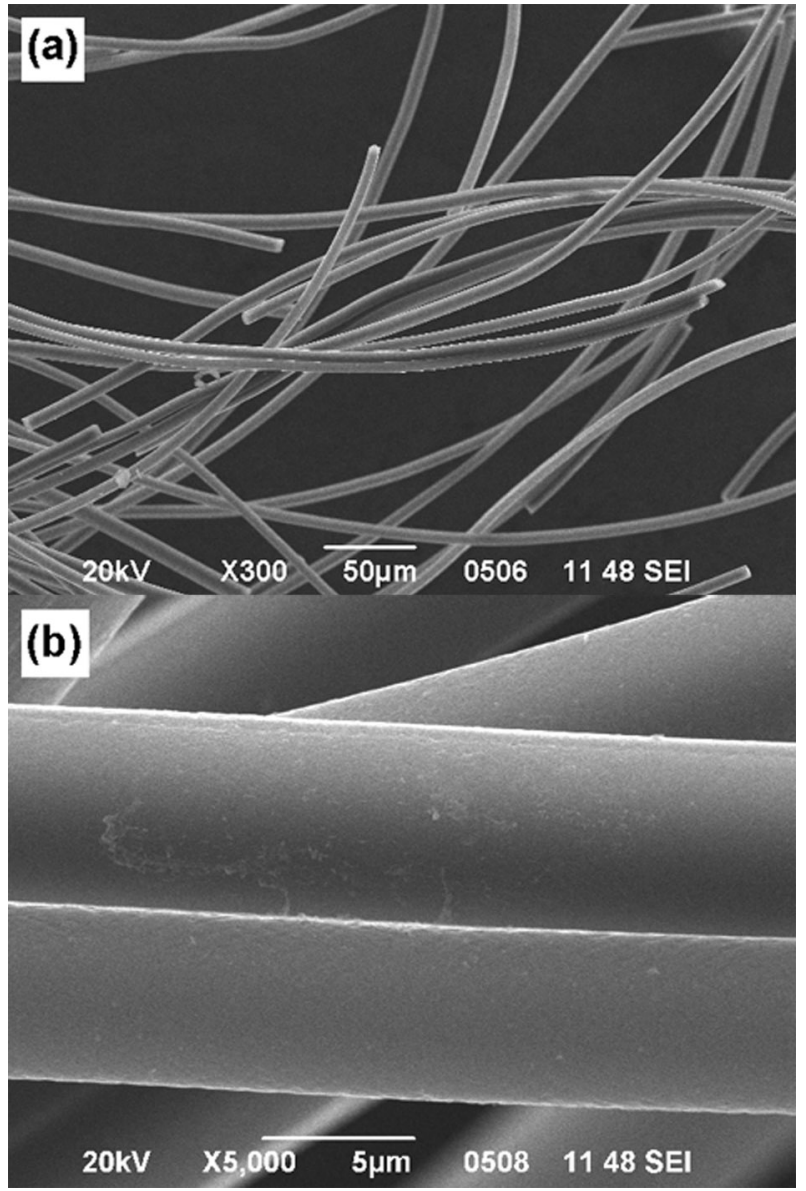

Figure 1. SEM micrographs of Cfs.

Figure 2a shows a small release of carbon oxides from the thermal decomposition of the oxygen-containing groups. $\mathrm{CO}$ release from phenol groups is observed at above $550{ }^{\circ} \mathrm{C}$. Gauss fitting of the $\mathrm{CO}_{2}$ profile shows the presence of carboxyl groups that have decomposed in the temperature range of $100-300{ }^{\circ} \mathrm{C}$. The anhydride and lactone groups decompose between 350 and $550{ }^{\circ} \mathrm{C}$, as can be seen from the profiles of $\mathrm{CO}$ and $\mathrm{CO}_{2}$. 
(a)

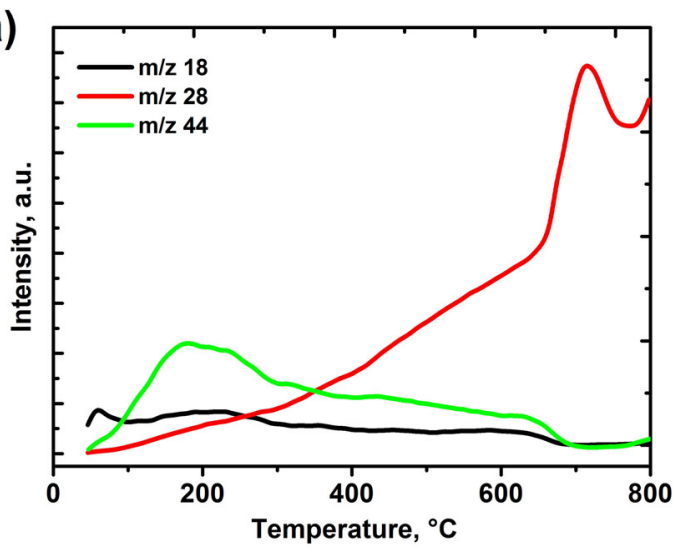

(b)

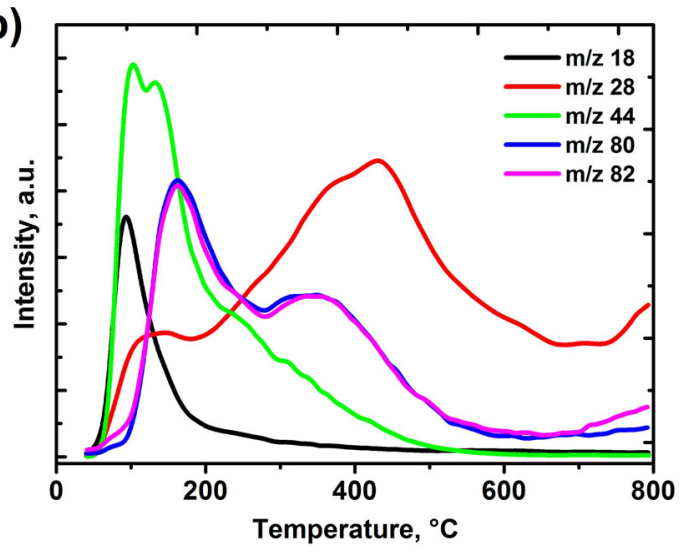

(c)

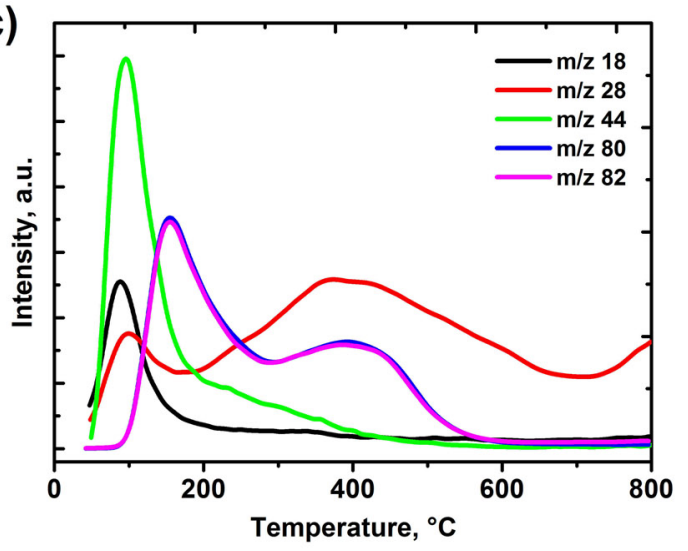

Figure 2. TPD MS profiles of (a) $\mathrm{CFs}$, (b) $\mathrm{CF} / \mathrm{Br}_{2}$, (c) $\mathrm{CF} / \mathrm{KBr}_{3}$.

Using the titration method, we found that the total amount of acidic groups was $0.92 \mathrm{mmol} / \mathrm{g}$.

About $0.4-0.5 \mathrm{mmol} / \mathrm{g}$ of bromine per $1 \mathrm{~g}$ of CFs can be grafted by bromination, regardless of the method used. Chemisorbed bromine atoms recombine with hydrogen

atoms and desorbed as the hydrogen bromide $\mathrm{HBr}$ desorbs in a wide temperature range. For $\mathrm{CF} / \mathrm{Br}_{2}$ and $\mathrm{CF} / \mathrm{KBr}_{3}, \mathrm{HBr}$ desorption began at temperatures as low as $90-100{ }^{\circ} \mathrm{C}$. Recorded as a function of sample temperature, the registered profile confirms the energetic difference of sites presented on the carbon surface and took part in the bromination and bromine atoms binding. In the $\mathrm{HBr}^{+}(\mathrm{m} / \mathrm{e}=82)$ mass channel, we observed desorption peaks at 150 and $160{ }^{\circ} \mathrm{C}$ and at 350 and $380{ }^{\circ} \mathrm{C}$. Each $\mathrm{HBr}$ desorption peak was broad and continuous in the ranges of $90-300$ and $300-590$ ${ }^{\circ} \mathrm{C}$. We found the area under the profile by integration between the limited temperatures for both peaks. The obtained areas were addressed to the low-temperature $\left(F_{1}\right)$ and high-temperature $\left(F_{2}\right)$ forms of $\mathrm{HBr}$. In fact, the absolute value of $F_{1}$ is about $1 / 3$ from the total content of $\mathrm{HBr}$ registered by TPD MS. The sample of $\mathrm{CF} / \mathrm{KBr}_{3}$ has the highest content of $F_{2}$. Table 1 showed close absolute values of the $F_{1} / F_{2}$ ratio found from the integration data.

Table 1. TPD MS and TGA data.

\begin{tabular}{|l|c|c|c|}
\hline \multirow{2}{*}{ Sample } & \multicolumn{3}{|c|}{ TPD MS } \\
\cline { 2 - 4 } & $\Delta t_{b}\left({ }^{\circ} \mathrm{C}\right)$ & $T_{1}, T_{2}\left({ }^{\circ} \mathrm{C}\right)$ & $F_{1} / F_{2}$ \\
\hline $\mathrm{CF} / \mathrm{KBr}_{3}$ & $90-570$ & 160,350 & 0.39 \\
\hline $\mathrm{CF} / \mathrm{Br}_{2}$ & $100-590$ & 150,380 & 0.36 \\
\hline \multirow{2}{*}{ Sample } & \multicolumn{3}{|c|}{$\mathrm{TGA}^{*}$} \\
\cline { 2 - 4 } & $* * \Delta t_{b}\left({ }^{\circ} \mathrm{C}\right)$ & $T_{1}\left({ }^{\circ} \mathrm{C}\right)$ \\
\hline $\mathrm{CF} / \mathrm{KBr}_{3}$ & $175-320$ & 220 \\
\hline $\mathrm{CF} / \mathrm{Br}_{2}$ & $180-310$ & 230 \\
\hline
\end{tabular}


The grafted bromine at ambient temperatures is stable. It does not hydrolyze at prolonged storage periods, both in air and in water. In addition, short-term boiling does not support hydrolysis, as evidenced by the absence of bromide ions in the filtrate. However, the surface bromine hydrolyzes rather quickly in the presence of alkalis at heating. When the brominated CFs reacted with $10 \% \mathrm{KOH}$ solution at room temperature, the bromine content decreased from 0.5 to 0.07 $\mathrm{mmol} / \mathrm{g}$ for the time of $5 \mathrm{~h}$. According to the TGA, the weight loss in the studied temperature range is $6.5 \%$ (Figure 3a).

This weight loss is because of the decomposition of the surface oxygen-containing groups. TPD MS showed peaks from water desorption $\left(105\right.$ and $\left.120^{\circ} \mathrm{C}\right)$, low-temperature $\mathrm{HBr}$ (220 and $230{ }^{\circ} \mathrm{C}$ ), and high-temperature $\mathrm{HBr}$ and carbon oxides $\left(540\right.$ and $\left.570{ }^{\circ} \mathrm{C}\right)$. According to the TGA data for $\mathrm{CF} / \mathrm{KBr}_{3}$, the $\mathrm{HBr}$ desorption occurs between 170 and $320^{\circ} \mathrm{C}$, with a peak maximum at $220-230{ }^{\circ} \mathrm{C}$ (Figures 3c and 3b).

TGA and TPD MS showed that the brominated CFs became more hydrophilic compared with the pristine CFs. They showed that the water desorption peak shifted to a side of higher temperatures by $30-50^{\circ} \mathrm{C}$. The temperature ranges of the $\mathrm{HBr}$ desorption found by the TPD MS and TGA are well consistent. However, $\mathrm{CF} / \mathrm{Br}_{2}$ showed higher absolute values than $\mathrm{CF} / \mathrm{KBr}_{3}$ by $10-30{ }^{\circ} \mathrm{C}$. Desorption of $\mathrm{HBr}$ occurs at a wide temperature range. This situation means that the grafted bromine groups differ by thermal stability. Besides, this bromine could be substituted by other types of functional groups.
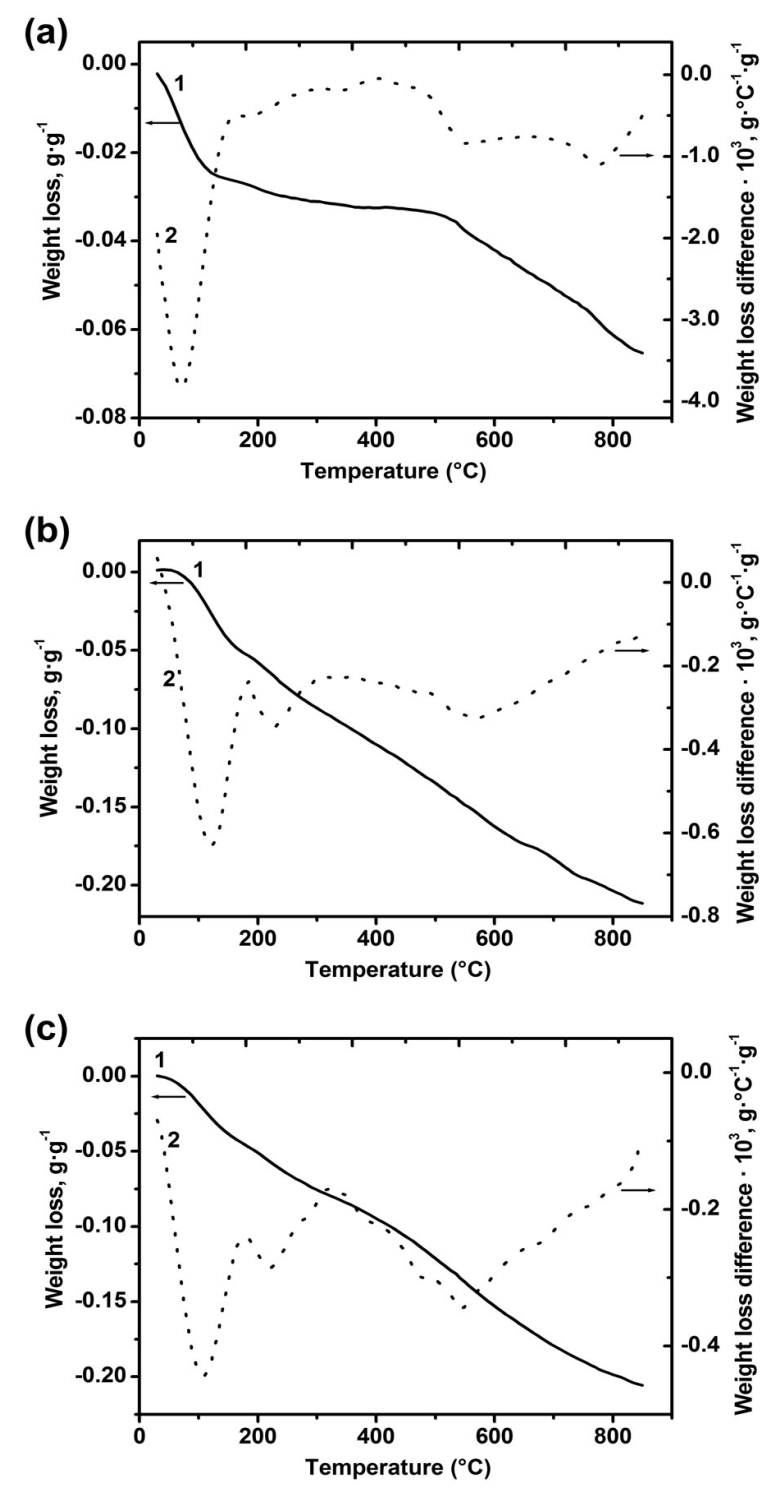

Figure 3. TGA: TG (1) and DTG (2) for (a) CF, (b) $\mathrm{CF} / \mathrm{Br}_{2}$, (c) $\mathrm{CF} / \mathrm{KBr}_{3}$.

Here below, we consider a series of aminated $\mathrm{CF} / \mathrm{Br}_{2} / \mathrm{X}$, where $\mathrm{X}=\mathrm{En}$, SuEn, $\mathrm{Et}_{2} \mathrm{~N}, \mathrm{MEA}$, and $\mathrm{Py}$, samples since $\mathrm{CF} / \mathrm{Br}_{2}$ contains more low-temperature bromine.

Scanning electron microscopy observation confirmed that the surface morphology maintains the same, without impairment of fiber properties (Figure 4.). 


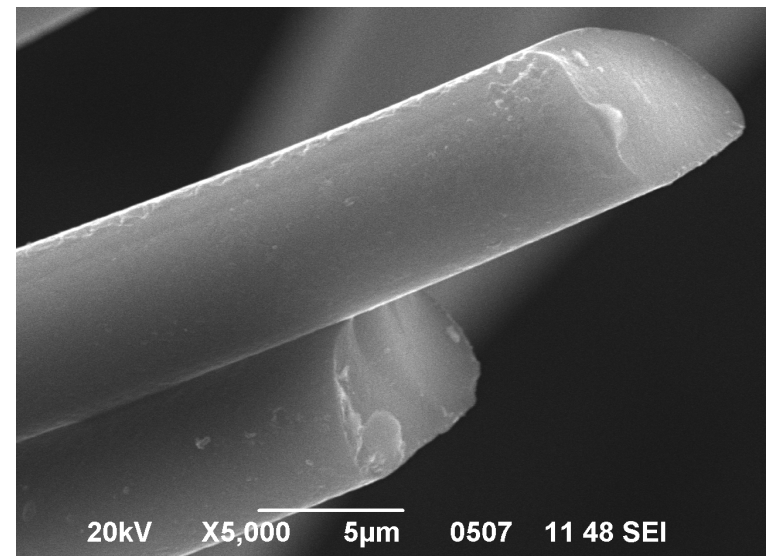

Figure 4. SEM micrograph of $\mathrm{CF} / \mathrm{Br}_{2} / \mathrm{MEA}$.
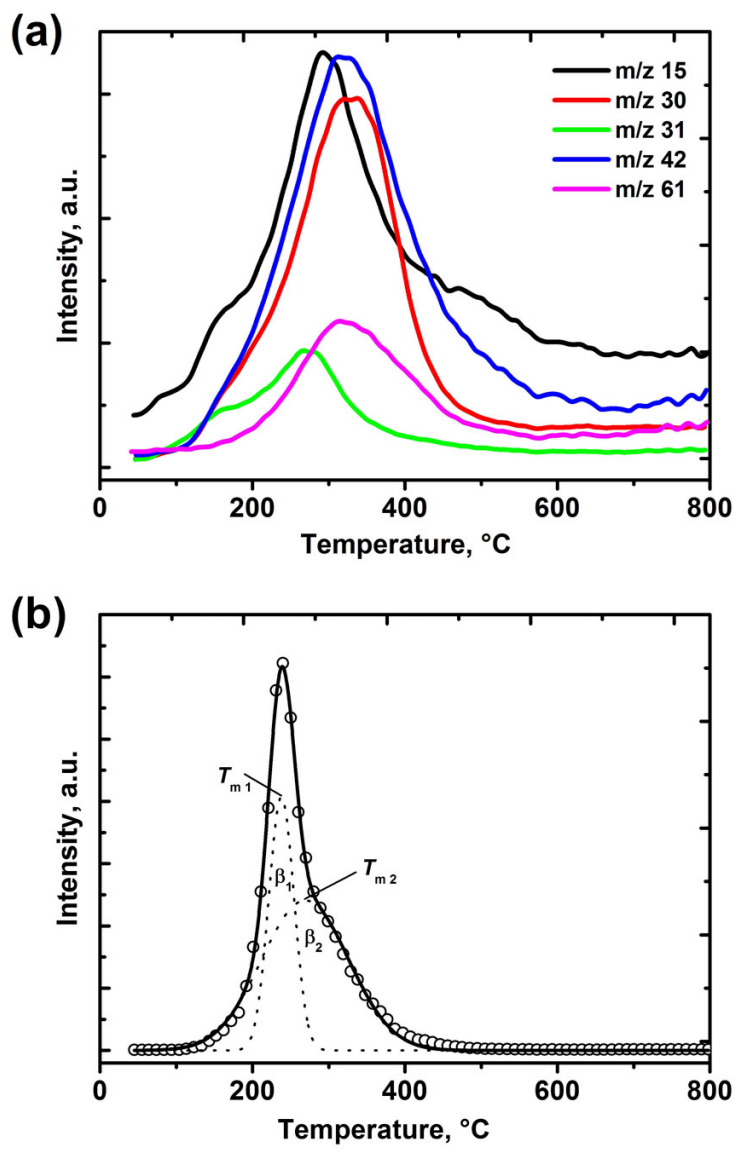

Figure 5. TPD MS profiles for (a) $\mathrm{CF} / \mathrm{Br}_{2} / \mathrm{MEA}$ and (b) $\mathrm{CF} / \mathrm{Br}_{2} / \mathrm{SuEn}$ at $\mathrm{m} / \mathrm{z} 64$ channel.

In all the ammonolysis experiments, bromine was fully reduced to the below detection. Signals of the amine fragments are recorded in the amine series $(\mathrm{m} / \mathrm{e}=30,44,58,72)$ mass channels. The intensity of the peaks of molecular amine ions is minimal due to the high intensity of decay processes.

Fragmentary ions of the so-called "amine series" are formed because of $\alpha$-cleavage of the $\mathrm{C}-$ $\mathrm{C}$ bond with subsequent rearrangement. The profile peak is between 150 and $400{ }^{\circ} \mathrm{C}$ (Figure 5a). TPD MS profiles of $\mathrm{CF} / \mathrm{Br}_{2} / \mathrm{SuEn}$ showed signals of $\mathrm{SO}_{2}^{+}(\mathrm{m} / \mathrm{z}=64)$, see Figure $\mathbf{5 b}$. Gaussian functions fit well the temperature profile of $\mathrm{SO}_{2}$ desorption with two components that have peaks at 240 and $300^{\circ} \mathrm{C}$.

Wide signals of the amine series tailored between 100 and $650{ }^{\circ} \mathrm{C}$ cause the thermal decomposition of such amino groups that have different chemical environments and contributed in the signals (see Figure 5a).

Figure 6 shows the temperature dependences of weight loss for $\mathrm{CF} / \mathrm{Br}_{2} / \mathrm{X}$, where $\mathrm{X}$ $=\mathrm{En}, \mathrm{SuEn}, \mathrm{Et}_{2} \mathrm{~N}, \mathrm{MEA}$, and Py.

We consider the temperature range of $140-420{ }^{\circ} \mathrm{C}$ to calculate the difference in the weight loss between the aminated and pristine CFs (Table 2). This difference is assigned to the weight loss that corresponds to the amino groups $\left(\Delta m_{\mathrm{N}}\right)$.

In the aforementioned temperature range, the weight loss corresponds to desorbing amine and carbon oxides, mainly $\mathrm{CO}_{2}$. The additional formation of oxygen-containing groups in the course of bromination followed by ammonolysis is insignificant. However, their thermal decomposition corresponds to about 
(a)

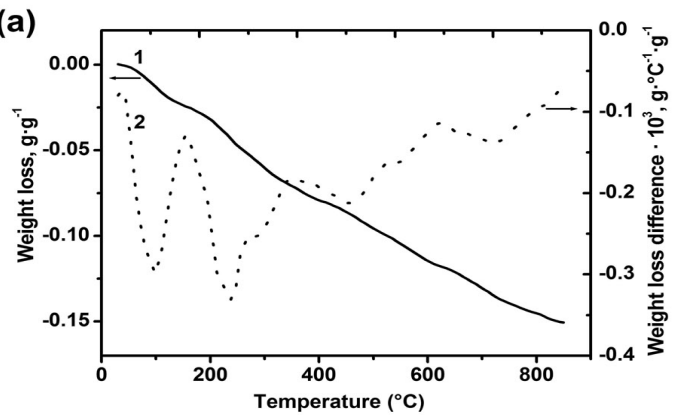

(b)

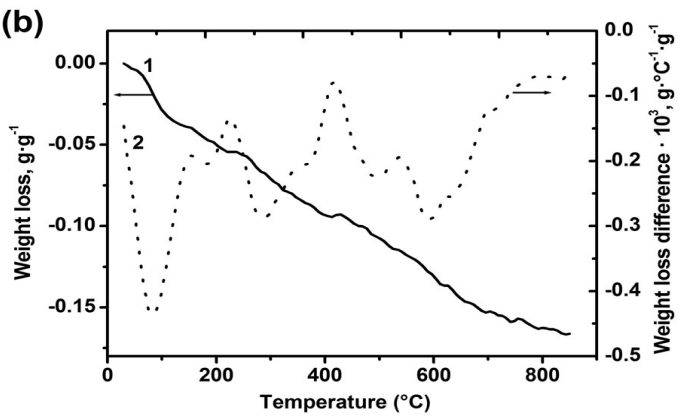

(c)

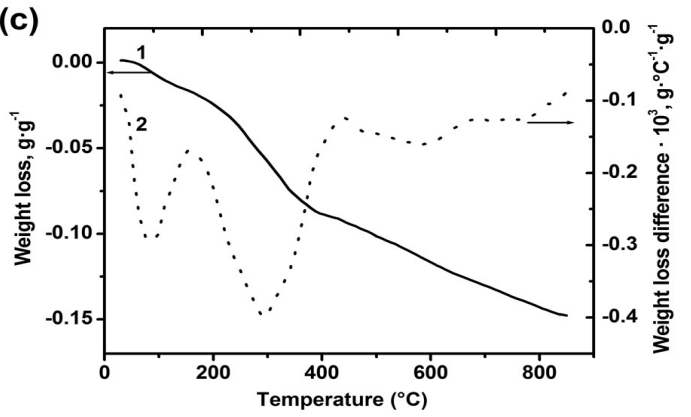

(d)

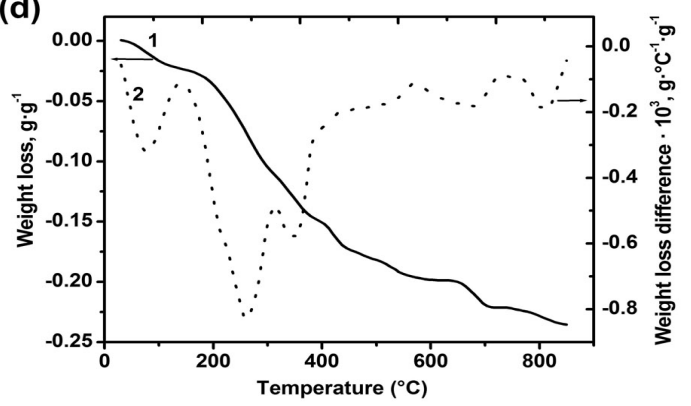

(e)

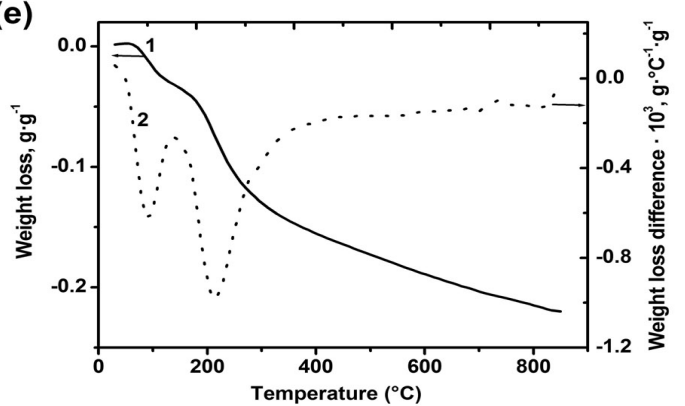

Figure 6. TGA: TG (1) and DTG (2) for (a) $\mathrm{CF} / \mathrm{Br}_{2} / \mathrm{En}$, (b) $\mathrm{CF} / \mathrm{Br}_{2} / \mathrm{Et}_{2} \mathrm{~N}$, (c) $\mathrm{CF} / \mathrm{Br}_{2} / \mathrm{MEA}$ (d) $\mathrm{CF} / \mathrm{Br}_{2} / \mathrm{Py}$, (e) $\mathrm{CF} / \mathrm{Br}_{2} / \mathrm{SuEn}$.
$10 \%$ of the total weight loss. That is why the surface concentration of the grafted amino groups $\left(C_{\mathrm{N}}\right)$ was calculated from the magnitude of $\Delta m_{\mathrm{N}}$ accounting for the aforementioned contribution.

Except for $\mathrm{CF} / \mathrm{Br}_{2} / \mathrm{SuEn}$, the peak temperature of the aminated CFs is by $30-60$ ${ }^{\circ} \mathrm{C}$ higher than the absolute value of the desorption temperature of $\mathrm{HBr}$ in the brominated CFs.

Table 2. TGA data for $\mathrm{CF} / \mathrm{Br}_{2} / \mathrm{X}$.

\begin{tabular}{|c|c|c|c|c|c|}
\hline $\mathrm{X}$ & $\begin{array}{c}\Delta m \\
(\mathrm{~g} / \mathrm{g})\end{array}$ & $\begin{array}{c}T_{\max } \\
\left({ }^{\circ} \mathrm{C}\right)\end{array}$ & $\begin{array}{c}\Delta t_{a} \\
\left({ }^{\circ} \mathrm{C}\right)\end{array}$ & $\Delta m / \Delta t_{a}$ & $\begin{array}{c}C_{\mathrm{N}} \\
(\mathrm{mmol} / \mathrm{g})\end{array}$ \\
\hline En & 0.15 & 260 & $150-400$ & 0.050 & 0.52 \\
\hline SuEn & 0.22 & 250 & $140-410$ & 0.119 & 0.56 \\
\hline $\mathrm{Et}_{2} \mathrm{~N}$ & 0.17 & 280 & $150-410$ & 0.048 & 0.44 \\
\hline $\mathrm{MEA}$ & 0.15 & 290 & $140-420$ & 0.051 & 0.55 \\
\hline Py & 0.24 & 260 & $140-390$ & 0.064 & 0.53 \\
\hline
\end{tabular}

We registered the high-temperature weight loss at above $420{ }^{\circ} \mathrm{C}$ for the aminated CFs. This weight loss, similar to that for the brominated $\mathrm{CFs}$, is from the thermal decomposition of the oxygen-containing groups, mainly phenolic groups [20]. Considering the absolute value of $T_{\max }$, one can range the aminated CFs in the descending order $\mathrm{CF} / \mathrm{Br}_{2} / \mathrm{SuEn}, \quad \mathrm{CF} / \mathrm{Br}_{2} / \mathrm{MEA}>$ $\mathrm{CF} / \mathrm{Br}_{2} / \mathrm{Py}>\mathrm{CF} / \mathrm{Br}_{2} / \mathrm{En}>\mathrm{CF} / \mathrm{Br}_{2} / \mathrm{Et}_{2} \mathrm{~N}$.

Temperatures at the thermal decomposition of the grafted amines determined by the TGA method substantially exceed the boiling points of pure amines. This 
means the chemical bonding and formation of amino groups in the surface layer of CFs. The chemical nature and molecular weight of amine have a minor impact on the surface concentrations of the grafted amino groups. The temperature range at which their thermal decomposition registered is close. This observation additionally confirms the covalent attachment of the amino groups. Thermal decomposition of larger groups at low temperatures $\left(\mathrm{CF} / \mathrm{Br}_{2} / \mathrm{SuEn}\right)$ can be explained by an increase in the number of decomposition sites (the number of bonds between nitrogen, carbon, and sulfur) and, as a result, an increase in the probability of breaking any bond in the grafted amine residue. As a rule, the breakage of one bond leads to the destruction of the whole grafted fragment. For $\mathrm{CF} / \mathrm{Br}_{2}$ treated with alcoholic amine solutions, the concentration of the amino groups was $0.44-0.56 \mathrm{mmol} / \mathrm{g}$ (Table 2). This absolute value corresponds well to $0.5 \mathrm{mmol} / \mathrm{g}$ of the preliminary grafted bromine. The aminated $\mathrm{CF} / \mathrm{Br}_{2} / \mathrm{X}$ can be used as carriers for the production of supported metal catalysts.

Aminated $\mathrm{CF} / \mathrm{Br}_{2} / \mathrm{X}$ showed higher thermal stability compared with that of the $\mathrm{CF} / \mathrm{Br}_{2}$ precursor. For aminated $\mathrm{CF} / \mathrm{Br}_{2} / \mathrm{X}$, the first weight loss is registered between 140 and $420{ }^{\circ} \mathrm{C} \quad$ (Table 2). These limiting temperatures are from 30 to $60{ }^{\circ} \mathrm{C}$ higher compared to the temperature range assigned to the thermal decomposition of bromine groups accompanied by $\mathrm{HBr}$ desorption.

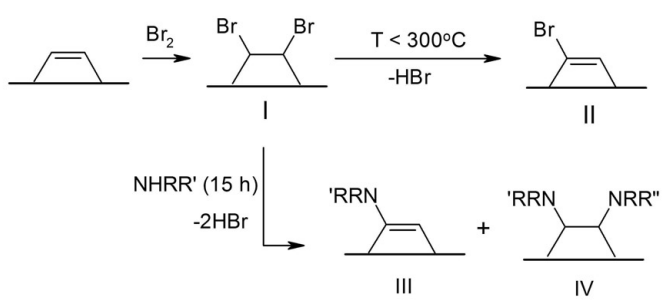

Figure 7. Scheme of reactions that passed on the carbon fiber surface.

Chemical transformations of the surface layer at bromination followed by ammonolysis are schematized below. Here, we claimed the bromine addition to double $\mathrm{C}=\mathrm{C}$ bond giving the precursor (I). At heating to $300{ }^{\circ} \mathrm{C}$, one molecule of $\mathrm{HBr}$ desorbs from the brominated fiber giving the product (II). Further heating above $300{ }^{\circ} \mathrm{C}$ is accompanied by radical processes. At high temperature, we suppose the thermal desorption of the second $\mathrm{HBr}$ molecule from the carbon surface. In ammonolysis, the grafted bromine is replaced by the amino group producing (III). Bromine was not detected in a series of aminated $\mathrm{CF} / \mathrm{Br}_{2} / \mathrm{X}$ samples. Since the concentration of amino groups reaches $0.44-0.56 \mathrm{mmol} / \mathrm{g}$, it is possible to attach the amine to the product (III) forming the diamine product (IV). The surface functionalization of CFs showed that the amount of amino groups is enough for the successful sorption of heavy metal ions and for preparing palladium catalysts of hydrogen oxidation [21]. 


\section{Conclusions}

Bromination in solutions gave active bromine precursors containing up to 0.5 $\mathrm{mmol} / \mathrm{g}$ bromine. According to TPD MS, bromine desorbs from the fiber surface in a wide temperature range, suggesting at least two forms of the grafted bromine. Chemical bromine bonding with the surface of carbon fibers confirmed by high desorption temperatures of $\mathrm{HBr}$. When $\mathrm{CF} / \mathrm{Br}_{2}$ reacted with alcoholic amine solutions, the amount of grafted amino groups was $0.44-0.56 \mathrm{mmol} / \mathrm{g}$. These absolute values supposed the total substitution of the grafted bromine. The obtained samples showed sufficient thermal stability. We can use them as carriers for the metal-containing catalysts and sorbents of heavy metal ions.

\section{References}

[1] Chen C, Li F, Guo Z, Qu X, Wang J and Zhang J. Preparation and performance of aminated polyacrylonitrile nanofibers for highly efficient copper ion removal. Colloids Surf A Physicochem Eng Asp 2019;568:334-44.

[2] Witik RA, Payet J, Michaud V, Ludwig C and Månson J-AE. Assessing the life cycle costs and environmental performance of lightweight materials in automobile applications. Compos Part A Appl Sci Manuf 2016;88:243-52.

[3] Fitzer E, Gkogkidis A and Heine $\mathrm{M}$. Carbon fibres and their composites (a review). High Temp - High Press 1984;16(4):363-92.

[4] Hockenberger AS. Surface modification of textiles for composite and filtration applications, $\mathrm{Ch}$. 11., Woodhead Publishing Series in Textiles 2009:23868.
[5] Inagaki M, Toyoda M, Soneda $\mathrm{Y}$ and Morishita T. Nitrogen-doped carbon materials. Carbon 2018;132:104-40.

[6] Beaumont PWR and Zweben CH (Eds.). Comprehensive Composite Materials II, Reference Work, 2nd Edition (2018, Elsevier, Amsterdam).

[7] Lee SM. (Ed.) Handbook of Composite Reinforcements. (1993, VCH, Weinheim).

[8] Nischith Raphael N, Namratha K, Chandrashekar BM, Sadasivuni KK, Ponnamma D, Smith AS, Krishnaveni S, Cheng C and Byrappa K. Surface modification and grafting of carbon fibers: A route to better interface. Progress Cryst Growth Character Mater 2018;64:75-101.

[9] Hayashida E, Takahashi Y, Nishia H and Uchiyama S. Electrolytic aminated carbon materials for the electrocatalytic redox reactions of inorganic and organic compounds. J Environ Sci 2011;23:S124-S127.

[10] Yang S, Li L, Xiao T, Zheng D and Zhang Y. Role of surface chemistry in modified ACF (activated carbon fiber)-catalyzed peroxymonosulfate oxidation. Appl Surf Sci 2016;383:142-50.

[11] Chen C, Li F, Guo Z, Qu X, Wang J and Zhang J. Preparation and performance of aminated polyacrylonitrile nanofibers for highly efficient copper ion removal. Colloids Surf A Physicochem Eng Asp 2019;568:334-44.

[12] Świetlik U, Grzyb B, Torchała K, Gryglewicz G and Machnikowski J. High temperature ammonia treatment of pitch particulates and fibers for nitrogen enriched microporous carbons. Fuel Proc Technol 2014;119:211-7.

[15] Zabihi O, Ahmadi M, Shafei S, Seraji M, Oroumei A and Naebe M. One-step aminofunctionalization of milled carbon fibre for enhancement of thermo-physical properties of epoxy composites. Compos Part A Appl Sci Manuf 2016;88:243-52.

https://doi.org/10.1016/j.compositesa.2016.06.005. 
[16] Wu Y and Tesoro GC. Chemical modification of Kevlar fiber surfaces and of model diamides. J Appl Polym Sci 1986;31:1041-59.

[17] Grishchenko LM, Diyuk VE, Mariychuk RT, Vakaliuk AV, Radkevich VZ, Khaminets SG, Mischanchuk OV and-Lisnyak VV. Surface reactivity of nanoporous carbons: preparation and physicochemical characterization of sulfonated activated carbon fibers. Appl Nanosci 2019; in press.

[18] Diyuk VE, Mariychuk RT and Lisnyak VV. Functionalization of activated carbon surface with sulfonated styrene as a facile route for solid acids preparation. Mater Chem Phys 2016;184:138-45.

[19] Diyuk VE, Mariychuk RT and Lisnyak VV. Barothermal preparation and characterization of micro-mesoporous activated carbons: Textural studies, thermal destruction and evolved gas analysis with TGTPD-IR technique. J Therm Anal Calorim 2016;124:1119-30.

[20] Grishchenko LM, Vakaliuk AV, Diyuk $\mathrm{VE}$ and et.al. From destructive $\mathrm{CCl}_{4}$ adsorption to grafting $\mathrm{SO}_{3} \mathrm{H}$ groups onto activated carbon fibers. Molec Cryst Liq Cryst 2018;673(1);1-15.

[21] Radkevich VZ, Senko TL, Wilson K, Grishenko LM, Zaderko AN and Diyuk VY. The influence of surface functionalization of activated carbon on palladium dispersion and catalytic activity in hydrogen oxidation. Appl Catal A: Gen 2008;335;24151. 